\title{
Friction embossing
}

\author{
W. Zou' ${ }^{1}$ W. K. Schomburg ${ }^{1}$
}

Received: 21 January 2020 / Accepted: 17 March 2020 / Published online: 30 March 2020

(C) The Author(s) 2020

\begin{abstract}
A new fabrication process for micro structures from thermoplastic polymers is presented. Two layers of thermoplastic polymer are placed onto a tool with micro structures. By a friction welding machine, the polymer surfaces are rubbed against each other generating friction heat and melting the polymer. The polymer adapts to the surface shape of the micro structures on the tool. Then, the movement of the machine stops and the polymer cools down and hardens in the shape of the micro structures. The entire process is finished within a few seconds and the required investment costs are in the range of some $10,000 €$ to approximately $200,000 €$. Compared to ultrasonic hot embossing, samples with larger overall dimensions can be fabricated and the heat distribution has been proven to be more homogeneous.
\end{abstract}

\section{Introduction}

Micro structures on the surface of substrates are fabricated at low cost from thermoplastic polymers. Such micro structures can be produced by a variety of processes such as injection molding, injection compression molding, hot embossing both with and without ultrasound (Heckele and Schomburg 2004; Giboz et al. 2007; Peng et al. 2014; Sackmann et al. 2015). While the other processes enable generating micro structures with larger aspect ratios and more precise replication of the tool structures, ultrasonic hot embossing allows for the shortest cycle times, the quickest change of polymer type and micro structure design and requires the least investment costs (Zou et al. 2019).

For ultrasonic hot embossing, an ultrasonic welding machine is employed melting the surfaces of thermoplastic polymer layers (Sackmann et al. 2015). Vibrations of a socalled sonotrode in the frequency range between 10 and $70 \mathrm{kHz}$ generate friction heat where the polymer is in contact to protruding micro structures on a tool (Fig. 1a). The heat melts the polymer which is pressed onto the tool, and therefore, adapts to the shape of the micro structures on its surface (Fig. 1b). Then the vibrations stop, the heat is dissipating into tool and sonotrode, and the polymer

\footnotetext{
W. Zou

zou@kemikro.rwth-aachen.de

1 RWTH Aachen University, KEmikro, Campus-Boulevard 30, 52074 Aachen, Germany
}

hardens in the shape of the micro structures. Then, a molded polymer piece is demolded.

The cycle time of ultrasonic hot embossing is just a few seconds because not the entire sample is heated up but only the portion near the surface to be embossed. The required investment costs are on the order of a few 10,000 €. However, the overall size of the samples is limited to the aria of the sonotrode. The largest sonotrode in our laboratory has an area of $12 \times 8 \mathrm{~cm}^{2}$. Larger sonotrodes can be fabricated, however, the power of ultrasonic welding machines is also limited and, as a consequence, the power available for generating vibrations is reducing when the size of the sonotrode area is increased.

The available power of ultrasonic welding machines is limited in principle. The ultrasonic vibrations are generated by driving a piezo stack at its resonance frequency. For larger power, a larger piezo stack is required and a larger piezo stack has a lower resonance frequency. Therefore, ultrasonic welding machines working at $20 \mathrm{kHz}$ provide more power and vibration amplitude than machines working at higher frequencies. Even lower frequencies at large power may cause damage to the ears of people. The audible range is below approximately $18 \mathrm{kHz}$.

Besides this, larger sonotrodes tend to show an inhomogeneous distribution of the vibration amplitude over their area (Kosloh et al. 2018). As a consequence, at a certain position under the sonotrode the micro structures may not yet be embossed completely, and at the same time, at another position the polymer is already decomposed and no longer suitable to form a proper micro structure. 


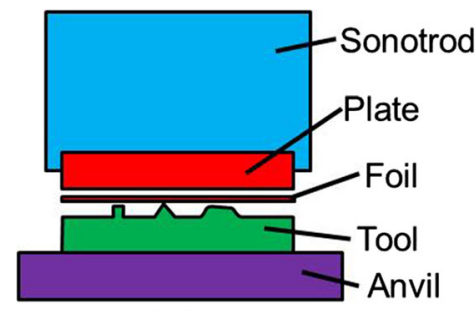

(a)

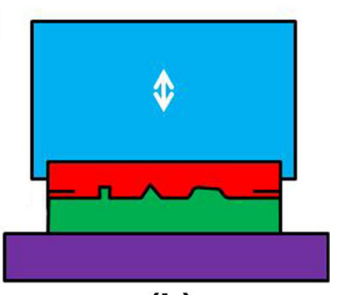

(b)
Fig. 1 Schematic drawing of ultrasonic hot embossing

Besides ultrasonic welding, friction welding is a process employed to join polymer parts by pressing their surfaces onto each other, melting them by heat generated by rubbing them against each other, and waiting for cooling down. Therefore, it has been investigated whether embossing of micro structures can also be achieved with friction welding machines. This process is called friction embossing and it is described in this paper.

\subsection{Fabrication process}

Friction embossing is schematically shown in Fig. 2. A tool with micro structures is fixed on the anvil of a commercially available friction welding machine. One layer from a thermoplastic polymer (Foil in Fig. 1a) is placed onto this tool and another polymer piece (Plate in Fig. 2a) is mounted on a holder above the tool. The two polymer layers are pressed onto each other by the machine and the anvil together with the tool is moved in lateral direction either back and forth by approximately $1 \mathrm{~mm}$ or along a circular path with a similar circumference length. The frequency of the movement and the pressing force are on the order of $200 \mathrm{~Hz}$ and $2 \mathrm{kN}$, respectively. The polymer layer on the tool is moved together with it because it is stuck on the micro structures and a frame surrounding them. If no foil is placed between tool and plate, the protruding micro structures on the tool scrape off particles from the polymer plate and not sufficient molten polymer is generated.

The frame is more protruding than all micro structures on the tool. The friction heat, generated this way between the polymer layers, is melting them and they are welded to a single piece and adapted to the shape of the micro structures on the tool (Fig. 2b). The frame surrounding the micro structures on the tool prevents the molten polymer from being squeezed out to the sides of the sample.

After a preset time called vibration time, the vibrations stop and the heat is dissipating into tool and holder while the polymer is hardening again. After a preset holding time, the upper part of the machine moves up and the sample is demolded from tool and holder (Fig. 2c).

The friction welding machine $\mathrm{M}-112 \mathrm{H}$ from Branson Ultraschall, Dietzenbach, Germany is shown in Fig. 3 with a heating plate and tool and a polycarbonate plate and foil, $4 \mathrm{~mm}$ and $300 \mu \mathrm{m}$ in thickness, respectively. A micro structure generated by friction embossing with this machine is shown in the insert at the lower right corner.

\subsection{Heat distribution}

Limitations in the overall size of polymer surfaces micro patterned by ultrasonic hot embossing are the limited power of ultrasonic welding machines and the inhomogeneous heat distribution generated below the sonotrode. Contrary to this, friction welding machines move the entire tool relative to the sample in lateral direction and there is no principle limitation in the available power because the drive can be constructed as large as desired. Therefore, all parts of the sample surface are exposed to the same friction if there are no micro structures on the tool and if polymer layers and anvil are even and well aligned to each other.

In Fig. 4, there are shown the heat distributions on polymer layers after ultrasonic and friction welding on an even anvil, respectively. Photos of the heat distributions were taken by the thermo camera THT70 from HT Instruments, Korschenbroich, Germany. The photos were taken from the side within $1 \mathrm{~s}$ after the holder or sonotrode, respectively, had been retracted from the sample.

Two layers from the polymer polyvinylchloride (PVC), $250 \mu \mathrm{m}, 40 \mathrm{~mm}$ and $60 \mathrm{~mm}$ in thickness, width and length, respectively, were placed on the anvil of the ultrasonic welding machine. Trigger force, pressing force, amplitude of ultrasonic vibrations, ultrasonic time and holding time were $130 \mathrm{~N}, 800 \mathrm{~N}, 32 \mu \mathrm{m}, 1 \mathrm{~s}$ and $0 \mathrm{~s}$, respectively. The thermo camera shows an inhomogeneous distribution of temperature on the surface of the polymer layer (cf. Figure $4 \mathrm{a}$ ). Maximum and minimum temperatures are $88^{\circ} \mathrm{C}$ and $40{ }^{\circ} \mathrm{C}$, respectively. With the parameters chosen for this experiment, the polymer layers were not welded to
Fig. 2 Schematic drawing of Friction embossing

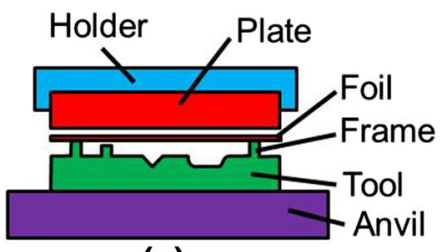

(a)

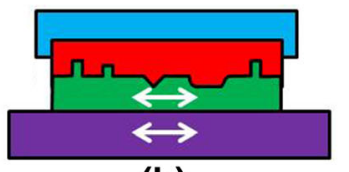

(b)

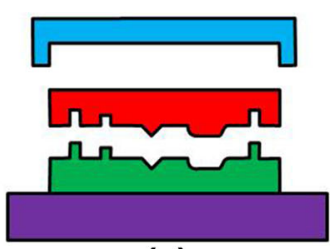

(c) 


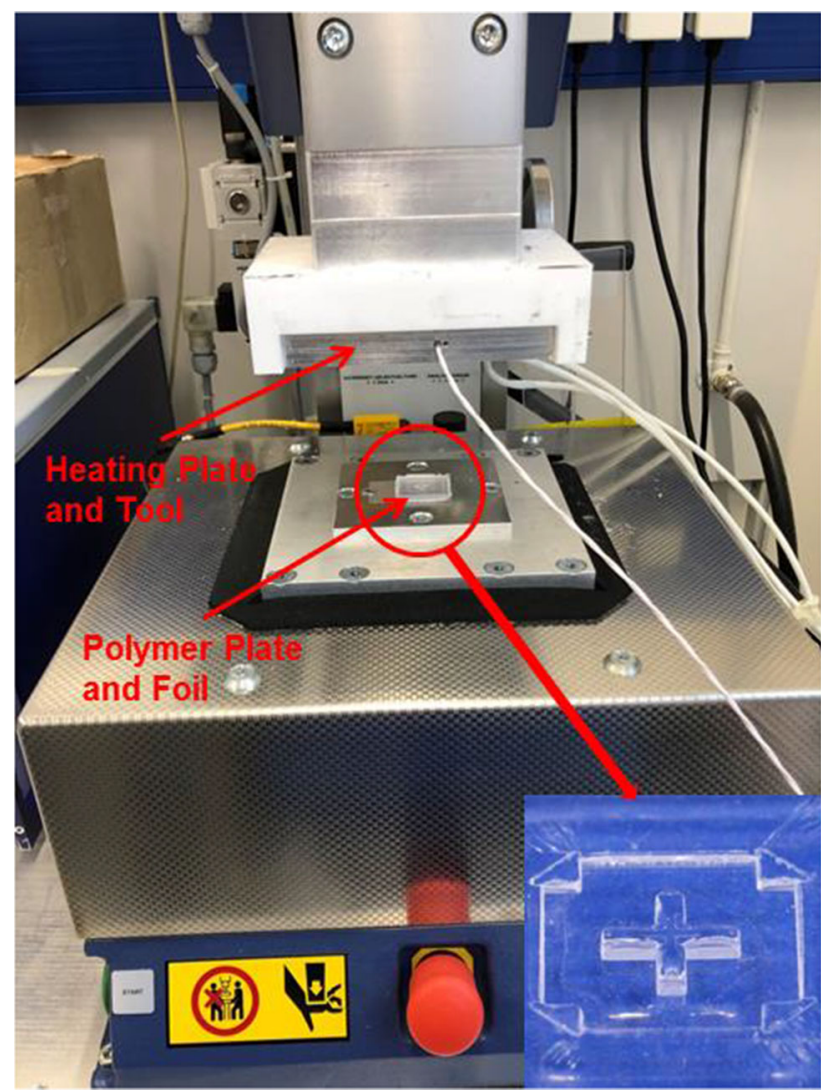

Fig. 3 Friction welding machine M-112H from Branson Ultraschall, Dietzenbach, Germany, and a micro structure generated by friction embossing

each other and the distribution of the generated heat is shown at a level lower than required for welding.

Two layers from PVC, $500 \mu \mathrm{m}, 40 \mathrm{~mm}$ and $60 \mathrm{~mm}$ in thickness, width and length, respectively, were mounted on the holder and the anvil of the friction welding machine, respectively. Pressing force, vibration amplitude (back and forth), vibration time and holding time were $1750 \mathrm{~N}$, $0.9 \mathrm{~mm}, 5 \mathrm{~s}$ and $0 \mathrm{~s}$, respectively. The thermo camera shows a comparatively homogeneous temperature distribution on the polymer surface with a maximum of $82{ }^{\circ} \mathrm{C}$ in the center and $72{ }^{\circ} \mathrm{C}$ at the rim (Fig. 4b). The polymer layers were not welded to each other because of the process parameters applied, but the temperature distribution shows that heat is generated more homogeneously by friction welding.

\subsection{Mold filling}

\subsubsection{Volume ratio of the tool}

If a cavity shall be generated in the polymer surface, a corresponding protruding micro structure on the tool is embossed into the polymer and the replaced polymer is squeezed out to the sides. However, if a recess in a tool needs to be filled with polymer, enough molten polymer need to be generated to fill the volume of the recess. Therefore, in the near of a recess some protruding micro structure should be designed providing the required volume of molten polymer.

All experiments described here were performed with plates and foils from the thermoplastic polymer polyethylene terephthalate (PET) from Polycasa Nischwitz $\mathrm{GmbH}$, Nischwitz, Germany. The foils and plates were $500 \mu \mathrm{m}$ and $4 \mathrm{~mm}$, respectively, in thickness and in all cases the friction welding machine $\mathrm{M}-112 \mathrm{H}$ from Branson Ultraschall, Dietzenbach, Germany, generating linear movements was employed. Initial tests showed that mold filling is achieved best if the maximum available pressing force $(1750 \mathrm{~N})$ and the maximum vibration amplitude $0.9 \mathrm{~mm}$ (back and forth from the center position). Therefore, all experiments were conducted at these parameters. Vibration time and holding time were both fixed for all experiments to $3 \mathrm{~s}$.

To investigate how large the protruding structure needs to be to fill a cavity in the tool, tools with five different designs were manufactured by milling into aluminum plates, $4 \mathrm{~mm}, 4 \mathrm{~cm}$ and $6 \mathrm{~cm}$ in thickness, width and length, respectively. The design is shown in Fig. 5. The volume of the recess is $19.35 \mu \mathrm{L}$.

Tools with different volume ratios of protruding to recess $(\mathrm{P} / \mathrm{R})$ were made to investigate its influence on the embossed structure. A recessing cross cavity was milled inside of a protruding cross bar. Five control marks, $100 \mu \mathrm{m}$ both in diameter and in depth, were drilled into the bottom of the cavity. Filling of the structure was considered complete when the control marks were visible on the
Fig. 4 Heat distribution on polymer layers after a ultrasonic and $\mathbf{b}$ friction welding on an even anvil
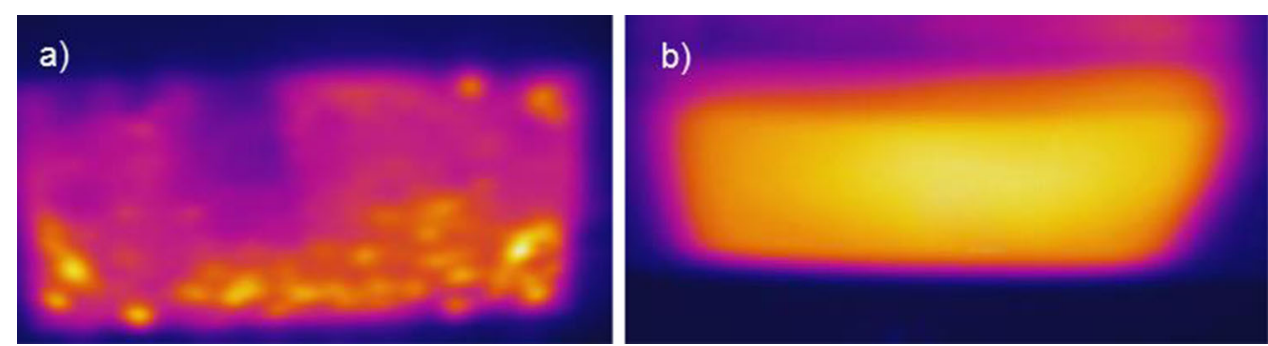


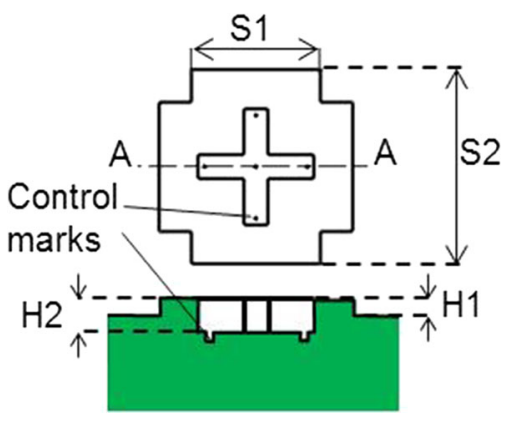

Fig. 5 Design of test structures as a top view and cross-section (not to scale)

embossed polymer structure. The volume ratio was varied by changing the surface area of the protruding cross bar. The dimensions of the tools with different volume ratio from 2.0 to 3.6 are shown in Table 1. The five tools have the same heights $\mathrm{H} 1=500 \mu \mathrm{m}$ and $\mathrm{H} 2=1000 \mu \mathrm{m}$ but different surface areas. Length and width of the recess cross bars were $7.2 \mathrm{~mm}$ and $1.5 \mathrm{~mm}$, respectively, in all cases.

A cut through a sample fabricated by friction embossing is shown in Fig. 6. The cavity in the tool was not completely filled.

To compare the results of the samples fabricated by tools with different $\mathrm{P} / \mathrm{R}$, the dimensions of the polymer structures were measured with a microscope and their volumes were approximately calculated from the structure heights and corner curvatures at the upper edges. The calculated ratio of the volumes of the sample structures and the recess $(\mathrm{S} / \mathrm{R})$ is shown in Fig. 7 as a function of $\mathrm{P} / \mathrm{R}$ : The larger the protruding structure on the tool is, the deeper the polymer is pressed into the recess. However, most of the molten polymer is squeezed out to the side.

\subsubsection{Frame around the structure}

To reduce the amount of polymer squeezed out to the side, a $500 \mu \mathrm{m}$ wide frame was milled at a distance of $1 \mathrm{~mm}$ around the structure (cf. Fig. 8). The frame is $700 \mu \mathrm{m}$ in height, which is $200 \mu \mathrm{m}$ higher than the structure so that the polymer melt cannot be squeezed out to the side.

Two tools with frame and with volume ratios of protruding and recess of 2.8 and 3.6, respectively, were milled to investigate the influences of a frame around the

Table 1 Dimensions and volume ratios P/R of the structures on the tools

\begin{tabular}{llllll}
\hline $\mathrm{S} 1[\mathrm{~mm}]$ & 5.7 & 8 & 8 & 8.6 & 9.2 \\
$\mathrm{~S} 2[\mathrm{~mm}]$ & 11.1 & 11 & 12 & 12.6 & 13.2 \\
Volume ratio P/R & 2.0 & 2.4 & 2.8 & 3.2 & 3.6 \\
\hline
\end{tabular}

Volume ratio $\mathrm{P} / \mathrm{R}=$ Volume ratio of protruding to recess

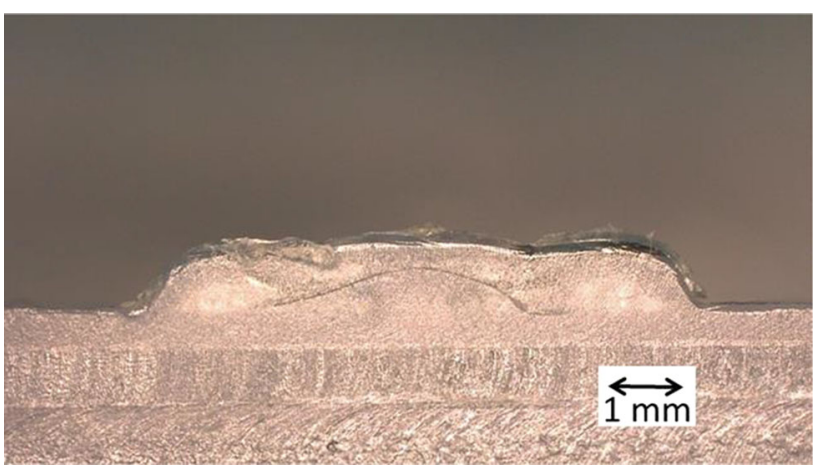

Fig. 6 Cut through the center beam of a polymer micro structure. The tool has not been filled completely

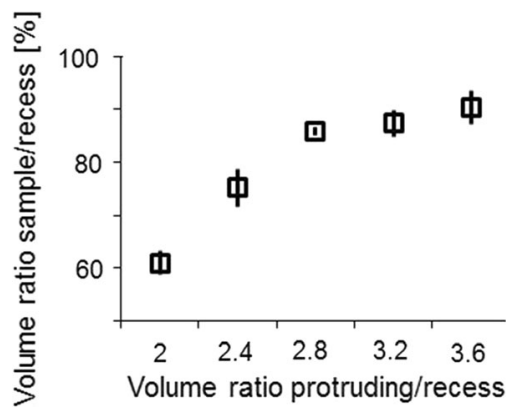

Fig. 7 Volume ratios of micro structures on the sample and in the recess of the tool as a function of volume ratios of protruding and recess structures of the tool

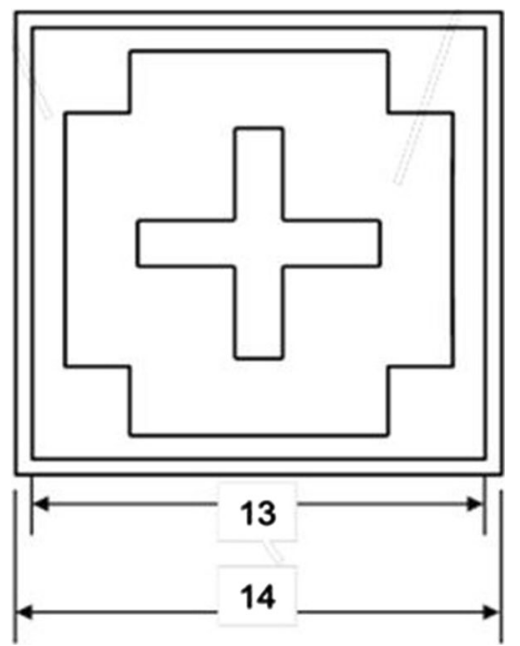

Fig. 8 Design of the frame around the test structure on the tool. All measures are in $\mathrm{mm}$

structure. Three samples were embossed with each tool and the volume ratios $\mathrm{S} / \mathrm{R}$ are shown in Table 2 .

Another tool with volume ratio $\mathrm{P} / \mathrm{R}=3.6$ and the distance between micro structure and frame increased to $5 \mathrm{~mm}$ was milled and nearly the same volume ratio $\mathrm{S} / \mathrm{R}$ was achieved. 
Table 2 Volume ratios S/R with and without a frame around the micro structures

\begin{tabular}{lll}
\hline Volume ratio P/R & Frame & Volume ratio S/R [\%] \\
\hline 2.8 & No & 86 \\
2.8 & Yes & 96 \\
3.6 & No & 90 \\
3.6 & Yes & 96 \\
\hline
\end{tabular}

The frame hinders molten polymer from being squeezed out to the side. Besides this, it may also clamp the foil better than the micro structures alone, and therefore, prevent the foil from sliding over the tool. Instead there is friction heat generated between polymer foil and plate. In addition, some air is enclosed inside of the frame and hinders mold filling. Therefore, another two tools with volume rations $\mathrm{P} / \mathrm{R}$ of 2.8 and 3.6 were designed and milled showing only a partial frame at the corners of a square around the micro structure (Fig. 9). This partial frame allows molten polymer and air to be squeezed out but clamps the foil at the corners of the square. The volume ratios $\mathrm{S} / \mathrm{R}$ are shown in Table 3 .

Obviously, a partial frame also helps to fill the recess in a tool but a frame enclosing the entire recess appears to be the better option. No air enclosures have been observed in any case. It is concluded from these measurements that the mold filling of friction embossing can be improved by a frame around the micro structure.

\subsubsection{Preheating of the tool}

Mold filling by friction embossing is limited because the molten polymer gets into contact to a cold wall when it is entering a cavity in the tool. This phenomenon is known from injection molding and ultrasonic hot embossing (Zou et al. 2019). The molten polymer near to the wall of a
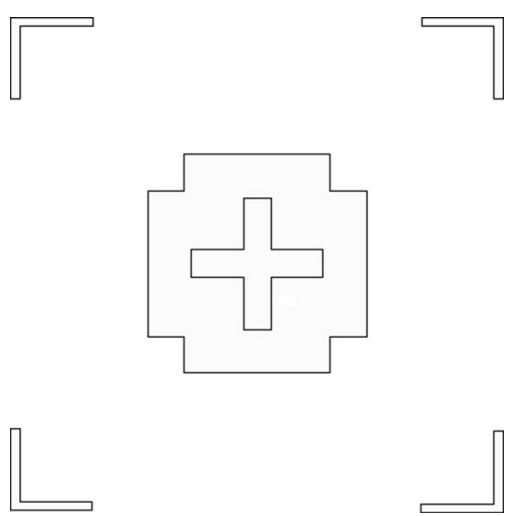

Fig. 9 Design of micro structures with a partial frame
Table 3 Volume ratios S/R

\begin{tabular}{lll}
\hline Volume ratio P/R & Frame & Volume ratio S/R [\%] \\
\hline 2.8 & Entire & 96 \\
2.8 & Partial & 92 \\
2.8 & No & 86 \\
3.6 & Entire & 96 \\
3.6 & Partial & 96 \\
\hline
\end{tabular}

cavity cools down faster and its viscosity is decreasing. As a consequence, the polymer reaches the center of the bottom of a cavity first and it is difficult to fill edges and corners. This is also recognized in Fig. 6 where the edges of the micro structure are not completely filled.

It has already been shown that in ultrasonic hot embossing mold filling can be improved when the tool is heated up near to its softening temperature (Sackmann et al. 2015). This way, the molten polymer is cooled down slower and the cavity is completely filled. The required holding time is extended only a little bit. Since the tool is kept at a constant temperature avoiding time consuming temperature changes, the cycle time is not extended significantly. Cooling down of the polymer may require a few seconds more but is much shorter than a variotherm process varying the temperature of the entire tool.

The influence of tool heating in friction embossing was investigated employing a tool of volume ratio $\mathrm{P} / \mathrm{R}=2.8$ without frame. The tool was heated to $70{ }^{\circ} \mathrm{C}$ by an electrical heating rod with a temperature control. The holding time was extended to $5 \mathrm{~s}$ and all other parameters were kept unchanged.

Figure 10 shows the samples fabricated without (left) and with (right) tool heating. The five control marks of the tool, which could not be found on the samples fabricated without tool preheating, are all shown on the samples fabricated with tool preheating.

Preheating of the tool leads to a retardation of the solidification process, thus, the cold wall effect is diminished.

It has not yet been investigated what are the smallest possible micro structures fabricated by friction embossing. It is expected that smaller structures than described in this paper can be fabricated this way. The smallest dimensions are not limited by the amplitude of the vibrations because the vibrations are only used to melt the polymer and it is adapting to the shape of the tool after the vibrations have been stopped. Choosing the optimum tool temperature for complete mold filling is the most important parameter for the successful fabrication of micro structures. 
Fig. 10 Micro structures generated by friction embossing without (left) and with (right) heating of the tool
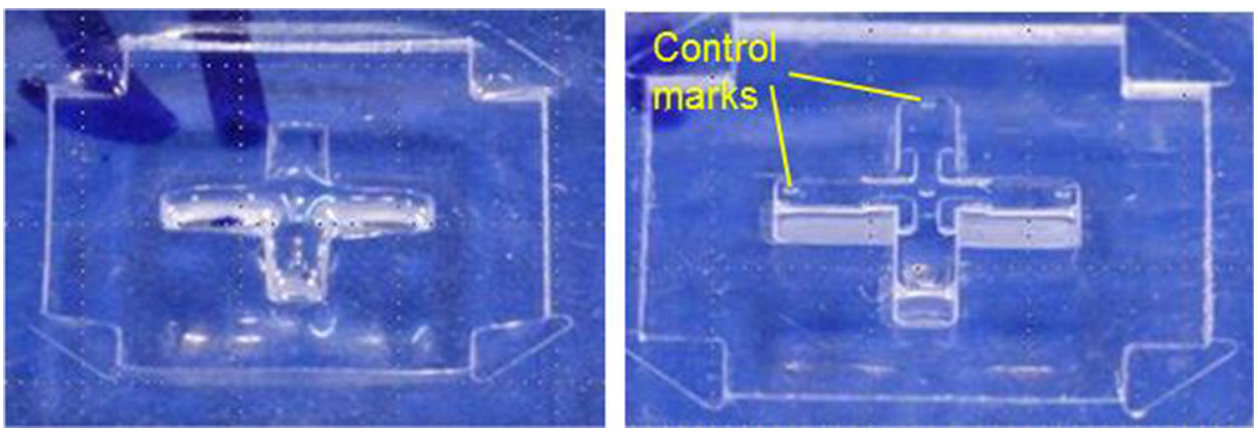

\section{Polymer flow}

The polymer flow during hot embossing with and without ultrasound was investigated by employing polymer layers from polypropylene (PP) foils, all $250 \mu \mathrm{m}$ in thickness, in the colors blue, red and yellow. At areas where the polymer has been molten the former layers have undergone a turbulent mixing by ultrasonic hot embossing (Fig. 11a). Less mixing of the layers occurs when no ultrasound is involved (Fig. 11b) (Kosloh et al. 2017).

To visualize the polymer flow during friction embossing, a transparent plate, $4 \mathrm{~mm}$ in thickness, and colored foils, all $250 \mu \mathrm{m}$ in thickness, from PP in the colors blue, red and yellow were employed for friction embossing. A similar tool as for the experiment in Kosloh et al. (2017) was applied. As shown in Fig. 11c, the blue layer under the top yellow layer can be hardly observed on the surface of the sample, which means that less turbulent flow occurs in friction embossing than in ultrasonic hot embossing. The cutaway view of the sample shows that the blue and red PP layers were mostly squeezed out to the side of the microstructure.
As shown above, a frame around the microstructure prevents the polymer melt from being squeezed out. Therefore, a tool such as in Fig. 8 with volume ratio $\mathrm{P} / \mathrm{R}=3.6$ and a frame around the structure with a distance of $5 \mathrm{~mm}$ to the microstructure was employed to investigate its influences on the polymer flow. The same arrangement of a transparent plate and colored foils as used for the samples shown in Fig. 11 were employed.

As shown in Fig. 12a, no mixing of the polymer layers can be observed on the surface of the sample. The cutaway view through one arm of the cross on the sample shows the layers in yellow, red, blue and transparent were not mixed with each other, a clear separation can be found between all the layers. It is assumed that, the polymer melt generated during friction embossing is subject to a laminar flow different from the one generated by ultrasonic hot embossing.

\section{Large scale friction embossing}

To investigate the friction hot embossing process on large scale, experiments were carried out with the circular friction welding machine ZMT 2.0 from Fischer Kunststoff-
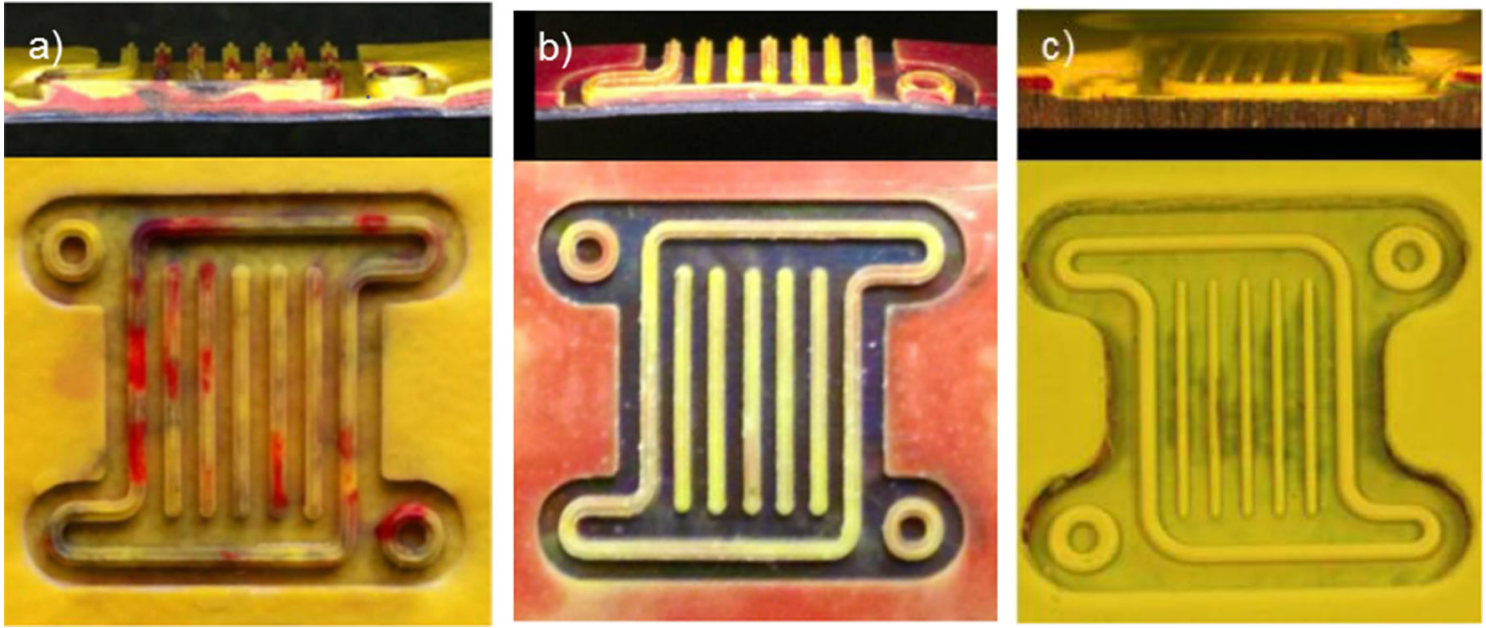

Fig. 11 Top view and a stripe cut out of a sample fabricated by hot embossing with (a) and without (b) ultrasound (Kosloh et al. 2017) and friction embossing (c) (color figure online) 
Fig. 12 Top view (a) and a stripe cut out (b) of a sample friction embossed from the tool with frame (color figure online)

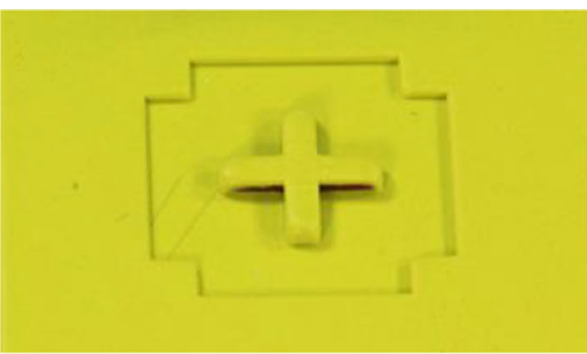

(a)

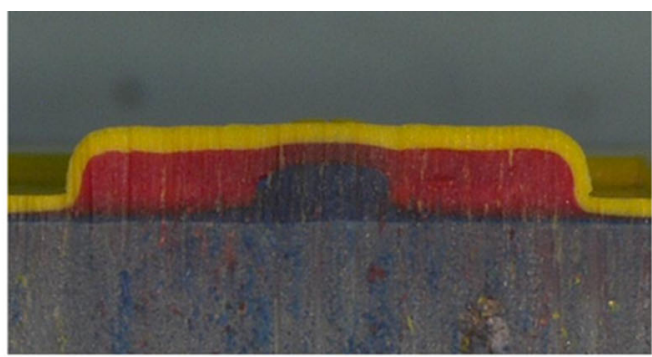

(b)
Schweißtechnik GmbH in Berkatal, Germany (cf. Fig. 13). 36 patterns of a protruding crossbar with four control marks and a partial frame around it were milled into an aluminum plate, $10 \mathrm{~mm}, 20 \mathrm{~cm}$ and $20 \mathrm{~cm}$ in thickness, width and length, respectively. The tool on a heating plate was placed into an isolation cubic made from Polytetrafluoroethylene (PTFE), these were fixed on the anvil and the polymer plate holder was fixed on the vibration head of the circular friction welding machine. The polymer foil was placed directly on the tool.

All experiments were performed with plates and foils from the thermoplastic polymer polyethylene terephthalate (PETG) from Polycasa Nischwitz GmbH, Nischwitz, Germany. The foils and plates were $500 \mu \mathrm{m}$ and $4 \mathrm{~mm}$, respectively, in thickness. Initial tests showed that embossing is achieved best by the minimum available radius of the circular movements $(0.7 \mathrm{~mm})$ and a

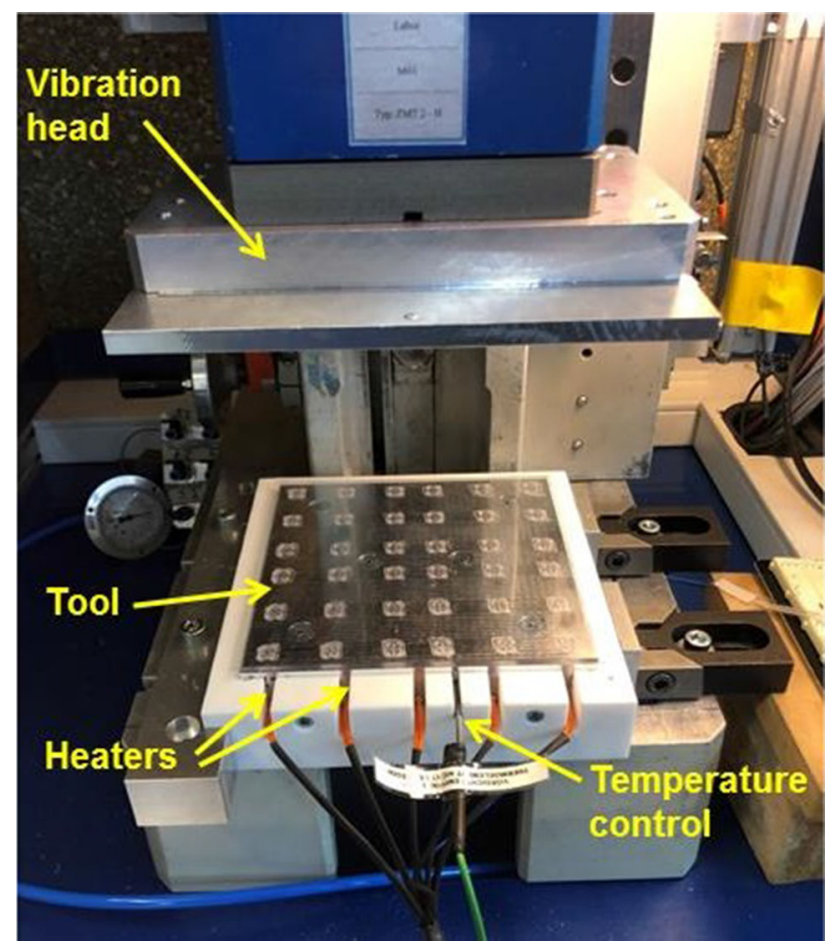

Fig. 13 Experimental design of the friction embossing process on the circular friction welding machine ZMT 2.0 preheating temperature of $70^{\circ} \mathrm{C}$. Therefore, all experiments were conducted with this radius and preheating temperature. Vibration time and holding time were fixed for all experiments to $10 \mathrm{~s}$ and $5 \mathrm{~s}$, respectively. This way, 33 samples were patterned by friction embossing (Fig. 14).

As shown in Fig. 15, all the patterns on the aluminum tool were completely embossed into the PETG plates as indicated by the control marks which are all visible on the embossed plates. Besides this, no decomposition of the polymer is observed. This indicates that friction heat and embossing force were similar everywhere on the surface of the plates. Pressing force and vibration frequency were $4700 \mathrm{~N}$ and $200 \mathrm{~Hz}$, respectively.

The surface of the plates was only rubbed and heated up where there are microstructures on the tool. The total area of all protruding micro structures is $860 \mathrm{~mm}^{2}$. Together with this area, also some part of the surface surrounding the microstructures was molten. This area is smaller in the center of the plates (approximately $1.1 \mathrm{~cm} \times 1.1 \mathrm{~cm}$ ) and larger at the rim (approximately $1.3 \mathrm{~cm} \times 1.3 \mathrm{~cm}$ ). After the experiments a measurement showed that the holder employed for friction embossing at the rim was $150 \mu \mathrm{m}$ higher than in the center. This may explain why more friction and heat had been generated at the rim.

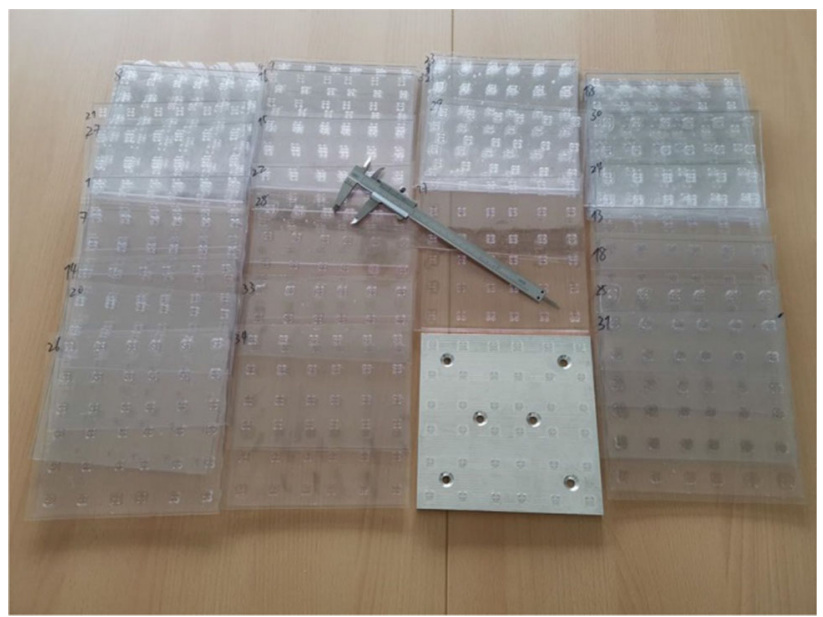

Fig. 14 Thirty-three friction embossed PETG plates and the employed tool, all with $20 \mathrm{~cm}$ edge length 
Fig. 15 Sample fabricated by circular friction embossing. Pressing force and vibration frequency were $4700 \mathrm{~N}$ and $200 \mathrm{~Hz}$, respectively

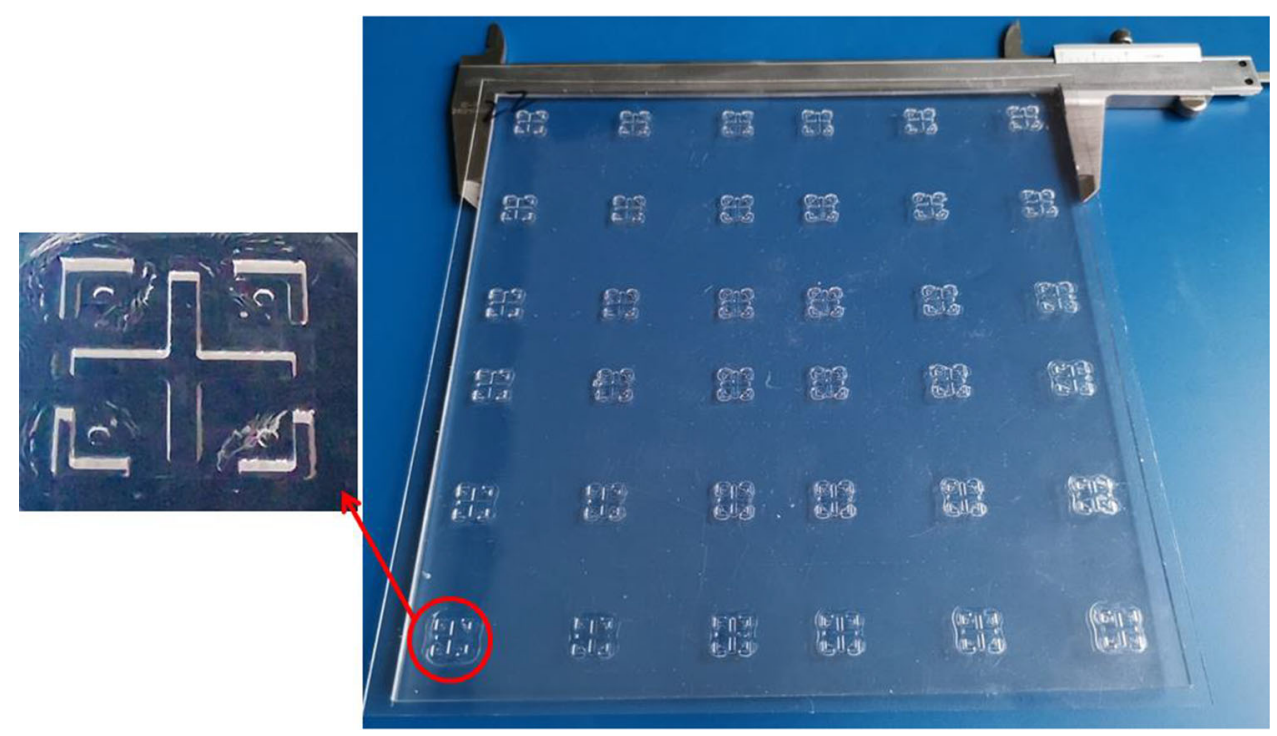

The total embossed area on the plates is estimated to be $4450 \mathrm{~mm}^{2}$. This is no principle limit, because friction welding machines can be equipped with more powerful drives. The maximum pressing force and vibration frequency of the ZMT 2.0 are $6.3 \mathrm{kN}$ and $240 \mathrm{~Hz}$, respectively, indicating that even larger areas could had been patterned and even more powerful machines are possible.

As shown in Fig. 16 the sample is curved after the process. This has to be expected because the molten foil is joined to the surface of the plate at an elevated temperature while most of the plate is not heated so much. After the bond of foil and plate is established the surface of the combination of former foil and plate is cooling down and shrinking according to the coefficient of thermal expansion of the polymer. This way, tensile stress develops at the plate surface causing the curvature. Besides this, the foil may also shrink because it had been extruded when it was fabricated. When it is heated up again, it tends to shrink in the direction of extrusion.

As a rough approximation, it is assumed that only the foil is shrinking on top of the plate and that it is joined to the plate everywhere. A temperature change $\Delta \mathrm{T}=62{ }^{\circ} \mathrm{C}$ from the softening temperature of PETG $\left[82{ }^{\circ} \mathrm{C}\right.$ (https:// www.polymehr.com/wp-content/uploads/technisches-daten blatt-petg.pdf)] to room temperature is assumed and Young's modulus and coefficient of thermal expansion are assumed to be $\mathrm{E}_{\mathrm{f}}=2.2 \mathrm{GPa}$ (https://www.polymehr.com/

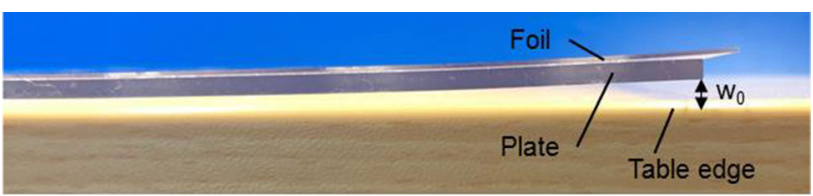

Fig. 16 Side view of a sample fabricated by friction embossing lying on a table wp-content/uploads/technisches-datenblatt-petg.pdf) and $\alpha_{\text {th }}=6.8 \times 10^{-5} /{ }^{\circ} \mathrm{C} \quad$ (https://www.polymehr.com/wp-con tent/uploads/technisches-datenblatt-petg.pdf), respectively. As a consequence, the stress $\sigma_{\mathrm{f}}$ generated in the film by cooling down is:

$\sigma_{\mathrm{f}}=\mathrm{E}_{\mathrm{f}} \alpha_{\mathrm{th}} \Delta \mathrm{T}=9.3 \mathrm{MPa}$

The stress $\sigma_{\mathrm{f}}$ of a thin film with thickness $\mathrm{d}_{\mathrm{f}}$ bending a substrate with thickness $d_{S}$, Poisson's ratio $v_{S}$ and Young's modulus $\mathrm{E}_{\mathrm{S}}$ is approximately calculated by the Stoney equation (Stoney 1909; Janssen et al. 2009):

$\sigma_{\mathrm{f}}=\frac{\mathrm{E}_{\mathrm{S}} \mathrm{d}_{\mathrm{S}}^{2}}{6\left(1-v_{\mathrm{S}}\right) \mathrm{R}_{\mathrm{c}} \mathrm{d}_{\mathrm{f}}}$.

The radius of curvature $R_{c}$ of the plates patterned by friction embossing is calculated as described in Zou et al. (2019): At the rim of the plates the distance $\mathrm{w}_{0}$ between the edge and the surface of an even table was measured. The curvature of the sample is approximated by a circle (cf. Fig. 17). The length $L$ of the chord corresponds to the edge length of the plate and its maximum distance to the circle is

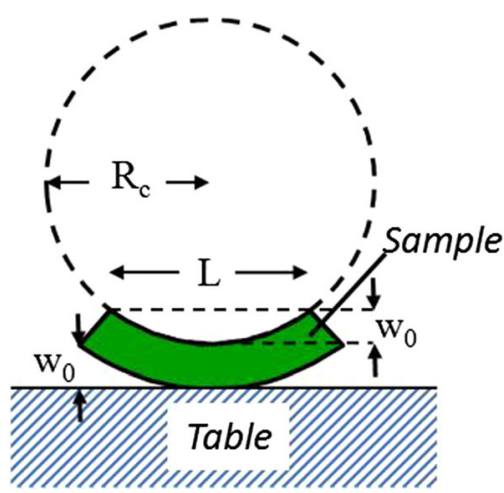

Fig. 17 Calculation of the radius of curvature (Zou et al. 2019) 
equal to the distance $w_{0}$ of the plate edge to the table. The radius of the circle is then calculated with the following equation (Bronstein-Semendjajew 1960):

$\mathrm{R}_{\mathrm{c}}=\frac{\mathrm{w}_{0}}{2}+\frac{\mathrm{L}^{2}}{8 \mathrm{w}_{0}} \approx \frac{\mathrm{L}^{2}}{8 \mathrm{w}_{0}}$.

The distance to the table was measured of 3 samples fabricated by friction embossing. Mean values and standard deviations of $\mathrm{w}_{0}$ and $\mathrm{R}_{\mathrm{c}}$ are $3.4 \pm 0.5 \mathrm{~mm}$ and $1480 \pm 240 \mathrm{~mm}$, respectively. The residual stress calculated by (2) assuming $\mathrm{E}_{\mathrm{S}}=2.0 \mathrm{GPa}, \mathrm{d}_{\mathrm{S}}=4 \mathrm{~mm}, \mathrm{~d}_{\mathrm{f}-}$ $=0.5 \mathrm{~mm}$ and $v_{\mathrm{S}}=0.4$ yields a residual stress of $12.0 \pm 1.7 \mathrm{MPa}$. This stress is on the same order of magnitude as the one calculated by (1) indicating that shrinkage due to cooling down of only a part of the plate has a significant effect on curvature. This also suggests that the curvature can be reduced if the plate is heated before the process up to a temperature below but near to the softening temperature of the polymer. This would not extend the cycle time very much but may partly reduce the curvature.

\section{Conclusions}

Friction embossing enables the fabrication of micro structures on the surface of thermoplastic polymer plates in cycle times of a few seconds. This is much quicker than injection molding of micro structures and lasts a bit longer than ultrasonic hot embossing.

The heat distribution generated by friction embossing is very homogeneous and allows patterning samples with areas of at least $4450 \mathrm{~mm}^{2}$. It is expected that even larger areas can be patterned with micro structures because, contrary to ultrasonic welding machines, there is no principle limitation of the power of the required friction welding machines. However, with the power of the machine also its costs will rise. A small machine can be purchased for a few $10,000 €$ and larger ones may cost almost $200,000 €$.

Preheating the tool is strongly recommended if cavities in the tool need to be filled. This extends the cycle time only a little bit because it slows down the cooling process, but micro cavities in the tool are filled much better. Besides this, a frame on the tool surrounding the micro structures supports mold filling by avoiding squeezing out polymer in lateral direction.

As a consequence of the partial heating of the sample, some curvature will occur. If this is a problem for a certain application, heating the sample before starting friction embossing may help.
Acknowledgements Open Access funding provided by Projekt DEAL.

Open Access This article is licensed under a Creative Commons Attribution 4.0 International License, which permits use, sharing, adaptation, distribution and reproduction in any medium or format, as long as you give appropriate credit to the original author(s) and the source, provide a link to the Creative Commons licence, and indicate if changes were made. The images or other third party material in this article are included in the article's Creative Commons licence, unless indicated otherwise in a credit line to the material. If material is not included in the article's Creative Commons licence and your intended use is not permitted by statutory regulation or exceeds the permitted use, you will need to obtain permission directly from the copyright holder. To view a copy of this licence, visit http://creativecommons. org/licenses/by/4.0/.

\section{References}

Bronstein-Semendjajew (1960) Taschenbuch der Mathematik. Verlag Harri Deutsch Leipzig, Frankfurt am Main. ISBN: 3-87144-0167

Giboz J, Copponnex T, Mélé P (2007) Microinjection molding of thermoplastic polymers: a review. J Micromech Microeng 17:R96-R109. https://doi.org/10.1088/0960-1317/17/6/R02

Heckele M, Schomburg WK (2004) Review on micro molding of thermoplastic polymers. J Micromech Microeng 14:R1-R14. https://doi.org/10.1088/0960-1317/14/3/R01

Janssen GCAM, Abdalla MM, van Keulen F, Pujada BR, van Venrooy B (2009) Celebrating the 100th anniversary of the Stoney equation for film stress: developments from polycrystalline steel stripes to single crystal silicon wafers. Thin Solid Films 517:1858-1867. https://doi.org/10.1016/j.tsf.2008.07.014

Kosloh J, Sackmann J, Šakalys R, Liao S, Gerhardy C, Schomburg WK (2017) Heat generation and distribution in the ultrasonic hot embossing process. Microsyst Technol 23:1411-1421. https:// doi.org/10.1007/s00542-016-2836-0

Kosloh J, Sackmann J, Krabbe S, Schomburg WK (2018) Measurement of temperature and pressure distribution during ultrasonic processes by PVDF sensor foils. Microsyst Technol 24:3729-3740. https://doi.org/10.1007/s00542-018-3832-3

Peng L, Deng Y, Yi P, Lai X (2014) Micro hot embossing of thermoplastic polymers: a review. J Micromech Microeng 24:013001. https://doi.org/10.1088/0960-1317/24/1/013001

Sackmann J, Burlage K, Gerhardy C, Memering B, Liao S, Schomburg WK (2015) Review on ultrasonic fabrication of polymer micro devices. Ultrasonics 56:189-200. https://doi.org/ 10.1016/j.ultras.2014.08.007

Stoney GG (1909) The tension of metallic films deposited by elecrolysis. Proc R Soc Lond A 82:172-175. https://doi.org/10. 1098/rspa.1909.0021

Zou W, Sackmann J, Striegel A, Worgull M, Schomburg WK (2019) Comparison of hot embossing micro structures with and without ultrasound. Microsyst Technol 25:4185-4195. https://doi.org/10. 1007/s00542-019-04469-1

Publisher's Note Springer Nature remains neutral with regard to jurisdictional claims in published maps and institutional affiliations. 